\title{
Depth-averaged velocity and bed shear stress in unsteady open channel flow over rough bed
}

\author{
Jnana Ranjan Khuntia ${ }^{1,}$, Kamalini Devi ${ }^{1}$, Sebastien Proust $^{2}$, and Kishanjit Kumar Khatua ${ }^{1}$ \\ ${ }^{1}$ Civil Engineering Department, National Institute of Technology Rourkela, 769008, Odisha, India \\ ${ }^{2}$ Irstea, UR RiverLy, centre de Lyon-Villeurbanne, 5 rue de la Doua CS 20244, 69625 Villeurbanne, \\ France
}

\begin{abstract}
Very few studies have been carried out in the past in estimating depth-averaged velocity and bed shear stress in unsteady flow over rough beds. An experiment is thus conducted to investigate the vertical and lateral velocity profiles under unsteady flow conditions in a rough open channel for various flow depths. One hydrogram is repeatedly passed through the rectangular flume with a fixed rigid grass bed. Using micro Pitot tube and Acoustic Doppler Velocimeter (ADV), the flow patterns are investigated at both lateral and longitudinal positions over different crosssections. For two typical flow depths, the velocities in both the rising limb and falling limb are observed. Hysteresis effect between stage-discharge (h $\sim$ Q) rating curve between rising and falling limbs is illustrated. Lateral distribution of depth-averaged velocity and bed shear stress are plotted at three different cross sections and compared with the steady flow conditions. In falling limb of an unsteady flow case, both depth-averaged velocity and bed shear stress distribution in the central region is higher than that of steady flow case. However, in the rising limb, the bed shear stress of unsteady flow is less than that of steady flow case. Further, in an unsteady flow, the magnitude of depth-averaged velocity is found to increase towards the downstream sections. Along the downstream positions, bed shear stress values increase for lower flow depths and decrease for higher flow depth cases.
\end{abstract}

\section{Introduction}

Flows in the natural rivers and channels are often unsteady. When discharge changes slowly, the problem of the unsteady flow can be solved with the condition of constant flow [1]. However, in some special cases such as reservoir operations, where discharge fluctuates rapidly, the knowledge of constant flow may lead to different or erroneous results when dealing with problems of sediment transport, scour, deposition, etc. [2]. So, the study of unsteady open channel flow has become an important issue for hydraulic engineering. Field studies show that, during the passage of a flood, the bed load movement, the suspended load distributions as well as the river processes are different from those in steady flow [3]. An understanding of the mean velocity, bed shear stress and turbulence characteristics under unsteady open channel flow conditions is needed e.g. to predict the

\footnotetext{
${ }^{*}$ Corresponding author: jnanaranjan444@gmail.com
} 
flood passage (hysteresis in the stage-discharge relationships between falling and rising limbs) and the river morphology processes dependent on unsteady effects. There are very few literature found on the experimental investigation in unsteady flow over the rough bed. $\mathrm{Tu}$ and Graf [4] used micro propellers to study the velocity distribution in unsteady open channel flow. They obtained the friction velocity as well as the shear stress distribution, but the turbulence was not measured.

Previous experimental research [5-8] investigated unsteady flow events in a laboratory fixed bank sand-bed channels using hydrographs of different shapes (e.g., trapezoidal, triangular etc.) and varying characteristics. General conclusions from the literature suggest that few experimental works have been done in response to unsteady flow event hydrograph. Despite this research, to date, no systematic effort has been done for the shape of the unsteady flow event hydrograph over a fixed rough bed and their flow variables.

Following the above consideration, the object of this research is to investigate the hydrograms and characteristics of flow variables over a fixed rough bed. The present research conducts an experiment in a tilting laboratory flume with a fixed bed with unsteady flow condition at National Institute of Technology, Rourkela, India. The mean flow velocity and bed shear stress over a rigid grass bed were measured to study the effect of unsteadiness on the flow characteristics and finally compared with experimental data of steady flow case for respective flow depths.

\section{Experimental setup and description of hydrogram runs}

The experiments were carried out in a $12 \mathrm{~m}$ long, $0.6 \mathrm{~m}$ wide and $0.6 \mathrm{~m}$ deep recirculating, rectangular, tilting flume in the Hydraulics Laboratory of Civil Engineering, National Institute of Technology Rourkela. The flume has glass walls in the testing section and the rest walls and bottom are of mild steel. The bottom of flume has been modified as a rough bed by fixing rigid grass along the channel bed. A schematic diagram of the experimental set-up is shown in Fig. 1. An electromagnetic flow meter is fitted with inlet pipe at upstream to measure the flow discharges. Three point gauges are fixed to measure the flow depth at different positions along the centre line of the flume. A longitudinal slope $\left(S_{0}\right)$ of approximately $1.2 \mathrm{~cm}$ in $10 \mathrm{~m}$ was set and kept unchanged throughout the experimental programme.

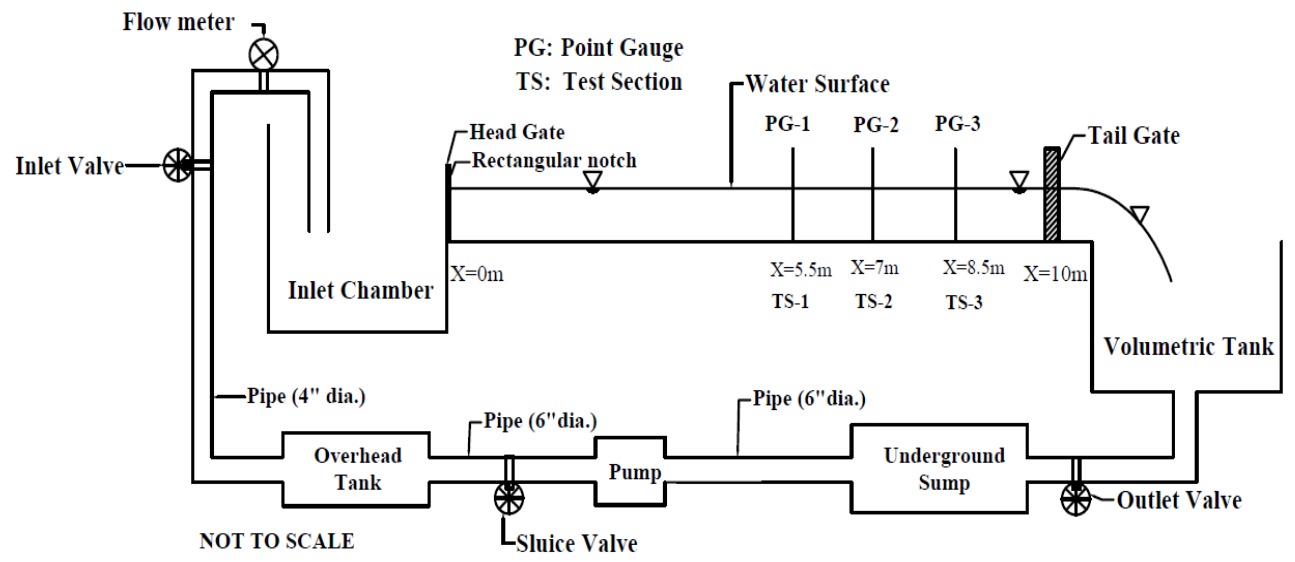

Fig. 1. A schematic diagram of the experimental set-up, NITR

A downstream tail gate is provided to maintain uniformity of flow for this experiment. The tailgate was fixed at a particular height to achieve the given flow depths in steady uniform cases. The same tail gate opening was maintained to achieve the respective flow 
depths in unsteady flow cases. The measurement of the flow variables has not been done other than the desired flow depth. To get the desired flow depth for the hydrogram, different tail gate settings with several experimental runs have been performed. Rails are provided to support and guide an instrument carriage to run laterally and longitudinally on the top of the flume walls to cover all the test points. The velocity fields were measured by a SonTek Micro 16-MHz acoustic Doppler velocimeter (ADV). The sampling rate is $50 \mathrm{~Hz}$ (the maximum) and the acquisition duration is 60s. Sampling volume of ADV is located approximately $5 \mathrm{~cm}$ below the down looking probe and was set to be minimum of $0.09 \mathrm{~cm}^{3}$. The $5 \mathrm{~cm}$ distance between the probe and sampling volume is assumed to minimize the flow interference. $\mathrm{ADV}$ can record the three directional velocities $U, V$ and $W$ in $X$ direction: along flume bottom, $Y$-direction: lateral to flume bottom and $Z$-direction: vertical to flume bottom respectively. The cross-section distribution of velocities was measured at three different positions (see Fig. 1), at $\mathrm{x}=5.5 \mathrm{~m}, 7 \mathrm{~m}$, and $8.5 \mathrm{~m}$. Then, Preston tube of outer diameter $4.77 \mathrm{~mm}$ was used to measure the velocities at the boundary along the whole perimeter of the flume. Geometry and roughness parameters of the experiment are given in table 1 .

Table 1. Geometry and roughness parameters for this experiment

\begin{tabular}{|c|c|c|}
\hline SI no & Item Description & Parameters \\
\hline 1 & Channel type & Straight \\
\hline 2 & Geometry of channel section & Rectangular \\
\hline 3 & Channel base width $(b)$ & $0.6 \mathrm{~m}$ \\
\hline 4 & Depth of channel & $0.6 \mathrm{~m}$ \\
\hline 5 & Bed slope $\left(S_{0}\right)$ & 0.0012 \\
\hline 6 & Length of flume & $12 \mathrm{~m}$ \\
\hline 7 & Length of test channel $(X)$ & $10 \mathrm{~m}$ \\
\hline 8 & Nature of surface bed & Dense rigid grass \\
\hline 9 & Flow condition & Un-steady \\
\hline 10 & Manning's $n$ of bed material & 0.0304 \\
\hline
\end{tabular}

The unsteady flow was established in the channel by passing a hydrogram over the fixed rough bed. This was done by one cycle of experiments with two steps (i.e. for getting rising and falling limb of hydrogram). For rising limb, the flume pipe inlet valve was opened and the constant head tank was filled with water by the pump continuously. When water reaches the full height of the overhead tank, the motor was stopped. To make the falling limb of hydrogram, water is fully allowed to pass through the experimental channel up to the time when the constant head tank gets empty. But, in this case, some amount of flow was still available in the channel which was fixed as the base flow. The flow behavior at the measuring sections remained similar as that in a long straight natural open channel with a mild bed slope. The ability to reproduce each hydrogram was essential given that only three point velocities could be observed on each limb during a single run. In the present work, only one hydrogram was studied with successful 198 runs. For maintaining the same flow depth, repetition of the experiments on the same hydrogram has been performed. More runs were taken for the same hydrogram to cover all the measuring points at three different positions for two different flow depths.

To obtain meaningful and representative values for the mean flow variables, it was necessary that flow conditions could be consistently reproduced, thus minimizing any underlying variability in the unsteady flows. To establish the bulk flow parameters that defined a hydrogram, measurements were made during all independent runs for the given hydrogram. The corresponding data for each variable was then ensemble-averaged and smoothened. For the steady flows, including the hydrogram base flow, a period of 10 
minutes (600 seconds) elapsed when a flow was established until measurements were taken or an unsteady flow hydrogram was initiated. This was ensured that flows were fully developed and in equilibrium. In each hydrogram run, two same depths of flow have been selected in each for rising and falling cases. For each depth of flow in rising or falling cases, measurements are performed at three positions.

\section{Results and discussions}

A total of 198 hydrograms was investigated during the experimental repetition. The flow and depth hydrograph in an unsteady flow run has shown in Fig. 2. The hysteresis effect of stage-discharge $(h \sim Q)$ rating curve between rising and falling limbs is illustrated in Fig. 3.
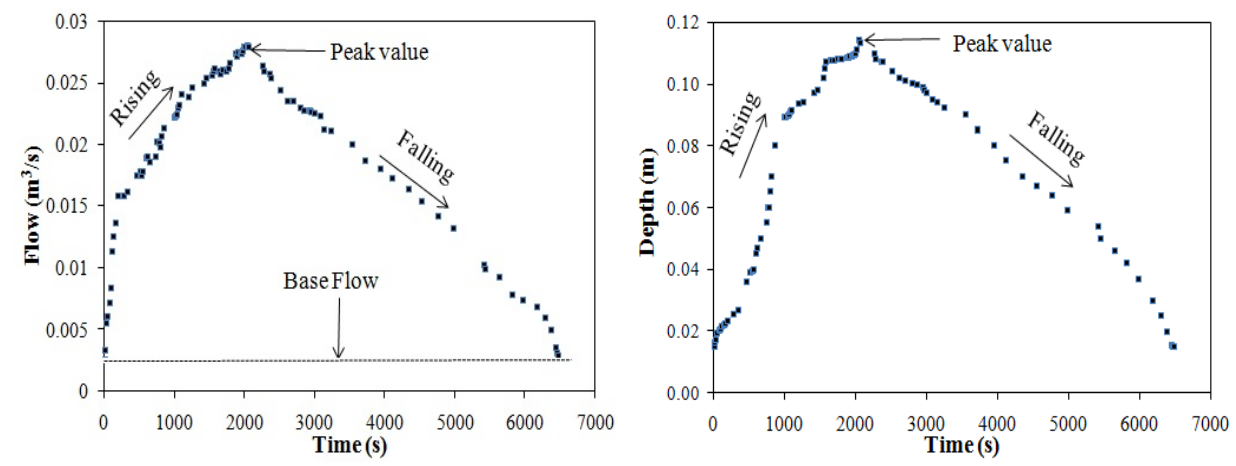

Fig. 2. Flow and depth hydrograph in an unsteady flow run

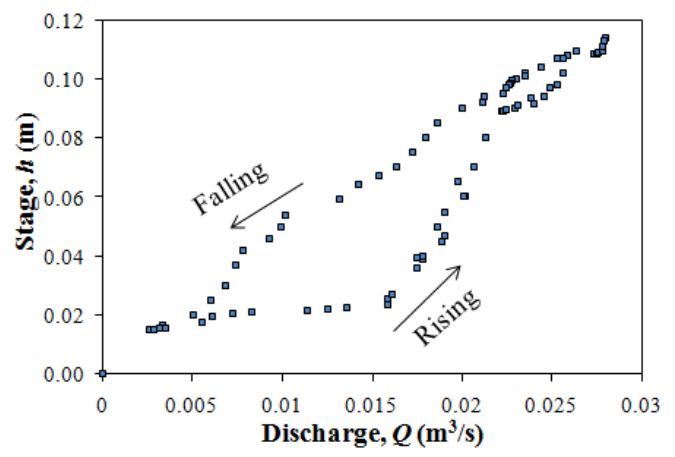

Fig. 3. Hysteresis effect in stage-discharge curve

To study the hydrogram, one skewness parameter $\eta=T_{r} / T_{f}$ proposed by [9], where, $T_{r}$ and $T_{f}$ are the duration of time for rising and falling limbs. This shape parameter represents hydrogram asymmetry. Based on this definition, one asymmetric hydrogram with the peak skewed towards the rising limb (i.e., $\eta=0.46$, referred to as 'skew-rising' or 'left-skewed' hydrogram) was observed over rigid grass bed (Fig. 2). The range of hydraulic parameters used in the experimental run of the hydrogram is given in Table 2.

After analyzing the variation of depth-averaged velocity and bed shear stress of a dense rigid rough bed for both steady and unsteady flow conditions, comparison of these flow variables has been made for both the rising and falling limb cases for a given flow depth. To acquire the same flow depth at three different locations in the particular unsteady flow conditions, several repetitions of the hydrogram has been done. Then the measurements of these flow variables at the corresponding positions are performed. 
Table 2: The range of hydraulic parameters used in the experimental runs

\begin{tabular}{|c|c|}
\hline Particulars & Value \\
\hline Slope & 0.0012 \\
\hline No of test runs & 198 \\
\hline Base flow $\left(\mathrm{m}^{3} / \mathrm{s}\right)$ & 0.0025 \\
\hline Water depth in base flow & $0.015 \mathrm{~m}$ \\
\hline Water depth at peak & $0.114 \mathrm{~m}$ \\
\hline Time duration for rising limb $\left(T_{r}\right)$ & $2040 \mathrm{~s}$ \\
\hline Time duration for falling limb $\left(T_{f}\right)$ & $4440 \mathrm{~s}$ \\
\hline Total duration of Hydrogram $(T)$ & $6480 \mathrm{~s}$ \\
\hline Range of Reynolds's number & $400-26970$ \\
\hline Range of Froude number & $0.10-0.42$ \\
\hline
\end{tabular}

\subsection{Depth-averaged velocity distribution}

The depth-averaged stream-wise velocity, $U_{d}$ is calculated by integrating local point stream wise velocities $(U)[10,12]$. The lateral distribution of $U_{d}$ at various x-positions are given in Fig. 4. The lateral distribution of $U_{d}$ has been plotted at three different postion. $U_{d}$ at each point is normalized by mean or bulk velocity, $U_{\text {mean }}$ (i.e., $Q / A$, where $Q$ is flow and $A$ is wetted area).
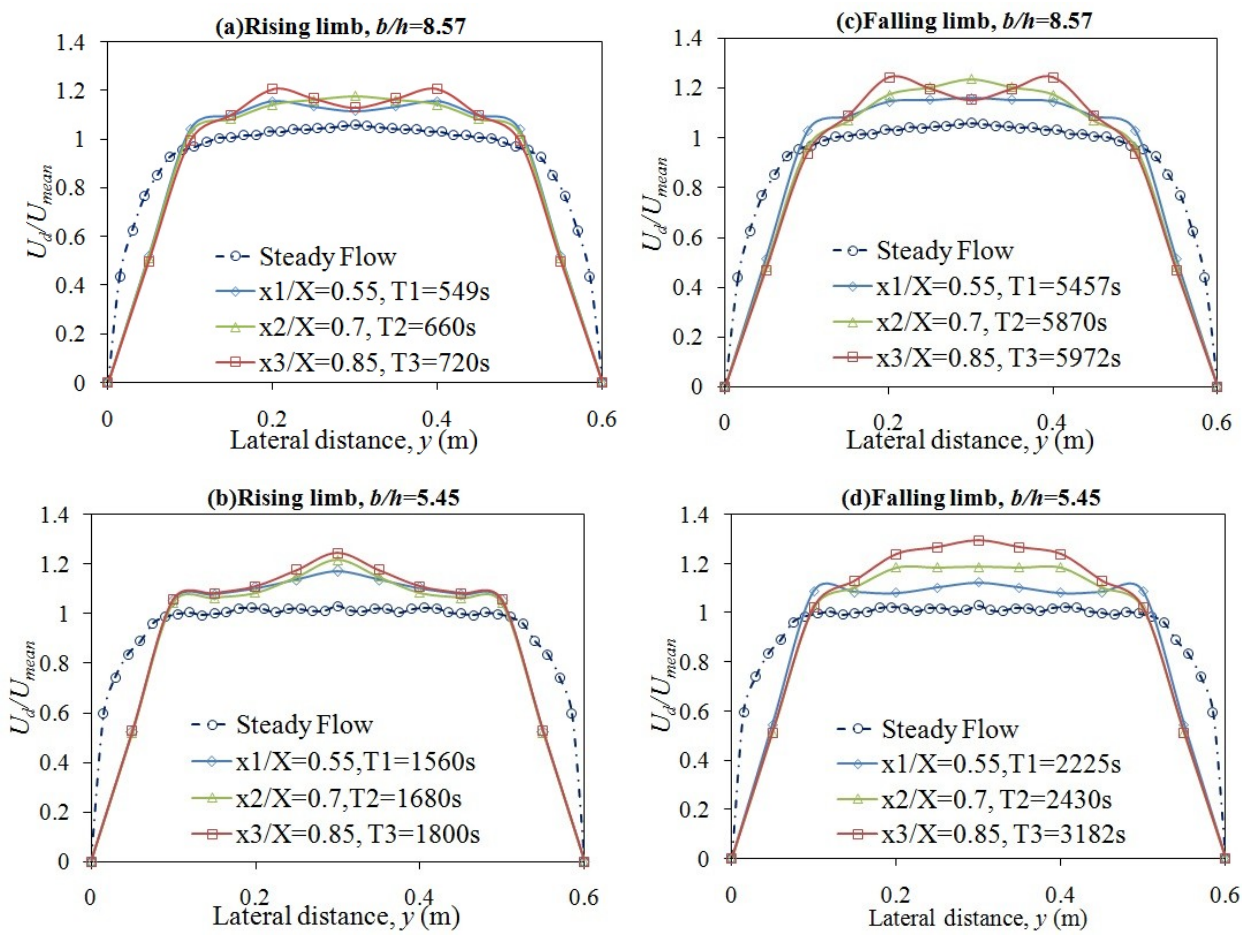

Fig. 4. Depth-averaged velocity for unsteady flow case of different longitudinal sections with steady flow case, (a) and (c) for lower flow depth, (b) and (d) for higher flow depth

For lower flow depth (i.e., flow aspect ratio, $b / h=8.57, h$ is flow depth) in rising limb, two peaks of normalized $U_{d}$ are found at both sides of the centre line. At the centre line of the channel, there is a fall of $15 \%$ of peak. As compared to steady flow normalized $U_{d}$ value of unsteady flow is higher except near the walls. Near the walls, there is sudden fall 
found in $U_{d}$ value. Similar behaviour is also found in falling limb in low depth case. However, the higher magnitude of normalized $U_{d}$ at central region posses lesser width as compared to rising limb case. This confirms that discharge in the rising limb higher than that for a falling limb case for the same depth of flow. Here the change in discharge is around $7 \%$.

For higher depth of flow (i.e., $b / h=5.45$ ), in rising limb case there are less changes noticed in the magnitude of normalized $U_{d}$ between steady and unsteady cases. For the unsteady flow, there is a peak at the central region at the three positions. But for falling limb case, there is higher difference in mangitude of normalized $U_{d}$ at the central region in downstream Section-3 (i.e., $\mathrm{x} 3 / \mathrm{X}=0.85$ ) as compared to the other two upstream sections, section 1 (i.e., $x 1 / X=0.55$ ) and section 2 (i.e., $x 2 / X=0.7$ ), where $X$ is the length of test reach. $\mathrm{x} 1, \mathrm{x} 2$ and $\mathrm{x} 3$ are the length of testing positions from upstream side.

At both higher flow depths and lower flow depths of an unsteady flow, accelerating effect dominates at the central region of the unsteady flow sections; hence there is an increase of Reynolds number occurs. This is visualized in higher values of normalized $U_{d}$ at the central region of cases of unsteady flow sections as compared to steady flow cases. Similar behavior in depth-averaged velocity distribution trends are also noticed due to decelerating effect of falling limb cases. Near the walls in unsteady flow both friction and unsteadiness causes more loss of energy, thus the drop in normalized $U_{d}$ values are found. The drop near to walls is higher for downstream sections as compare to upstream sections.

The depth-averaged velocity increases towards the downstream positions. This is because of more energy loss expected to occur at upstream sections of an unsteady flow as compared to the downstream sections resulting the lesser velocity at upstream sections. However, unsteady effects gradually stabilize towards the downstream sections causing lower energy loss and hence produces higher value of depth-averaged velocity.

\subsection{Bed shear stress distribution}

Preston tube technique [11] is utilized to calculate bed shear stress along the bed of the channel. The bed shear stress distributions are shown in Fig. 5. Bed shear stress at each point of the bed is normalized to $\rho g H S_{0}$, where $\rho$ is density of water, $g$ is acceleration due to gravity, $H$ is the flow depth and $S_{0}$ is bed slope of the channel.

Similar trends of depth-averaged velocity are observed for bed shear stress $\left(\tau_{b}\right)$, i.e., high values of shear stress are found for unsteady flow case. This is because of the relationship between $U_{d}$ and $\tau_{b}$ (i.e., $\tau_{b}=f \rho U_{d}{ }^{2} / 8$ ), where $f$ is boundary friction factor. In low flow depths, unsteady flow causes more energy loss due to boundary friction and unsteadiness of the flow producing more bed shear stresses.

In higher flow depths, similar trends are found in both rising and falling limbs cases. For three test sections, results of $\tau_{b}$ distribution are observed (see Fig. 5) for lower and higher flow depths. In the rising limb cases, both in lower and higher flow depth cases, the normalized $\tau_{b}$ value of unsteady flow is lower as compared to steady flow case.

But in falling limb case it reverses i.e., $\tau_{b}$ values for unsteady case is higher as compared to steady case. Similar case to depth-averaged velocity, here also a sudden fall of normalized $\tau_{b}$ values are found near the wall regions. For higher flow depth cases both for falling and rising limb cases, there are two peaks of normalized $\tau_{b}$ values are found at the region far away from the central line (i.e., located at $1 / 4^{\text {th }}$ of the width).

Bed shear stress values increase for lower flow depths and decrease for higher flow depth cases. This is because the effect of accumulated and higher value of friction factor is produced at the downstream sections. Thereby increase of bed shear stress is found at downstream sections as compared to the upstream sections. For higher flow depths, the effect of bottom friction decreases maintaining the similar trend of depth-averaged velocity. 

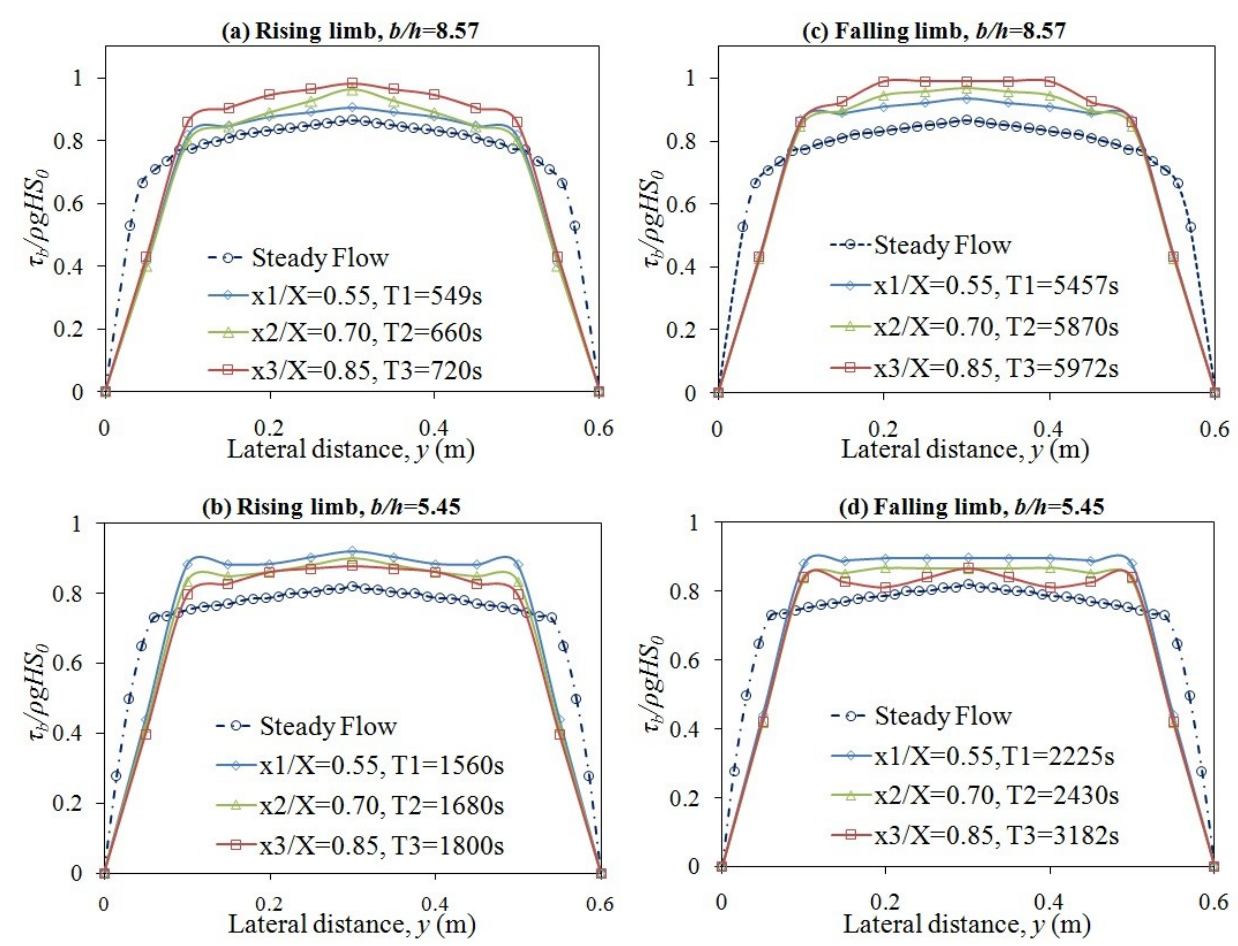

Fig. 5. Bed shear stress distribution for unsteady flow case of different longitudinal sections with steady flow case, (a) and (c) for lower flow depth, (b) and (d) for higher flow depth

\section{Conclusions}

From the experimental investigation in unsteady flow over a rough bed channel, the following conclusions have been drawn:

- From the stage-discharge $(\mathrm{h} \sim \mathrm{Q})$ rating curve between rising and falling limbs, hysteresis effect for unsteady flow case has been studied. For the same flow depth, the discharge in the rising limb is higher than that of the falling limb case.

- Both the depth-averaged velocity and bed shear stress in unsteady flow are found to change from positions to position though there having the same flow depths. These are also found to be different from the result of a steady flow case.

- For lower flow depth in a rising limb, the higher depth-averaged velocities as compared to that in steady flow case are found and gradually these values reduce towards downstream sections. Similar behavior is also found in falling limb in low depth case. However, the higher magnitude of $U_{d}$ at central region posses lesser width as compared to rising limb case. This confirms that discharge in the rising limb higher than that for a falling limb case for the same depth of flow.

- In the rising limb cases, both in lower and higher flow depth cases the bed shear stress value of unsteady flow is lower as compared to steady flow case. But in falling limb case it reverses i.e., bed shear stress values for unsteady case is higher as compared to steady case. Similar case to depth-averaged velocity, here also a sudden fall of bed shear values are found near the wall regions. For higher flow depth cases both for falling and rising limb cases, there are two peaks of $\tau_{b}$ values are found at the region far away from the central line (i.e., located at $1 / 4^{\text {th }}$ of the width). 
- The depth-averaged velocity increases towards the downstream positions. This is because of more energy loss expected to occur at upstream sections of an unsteady flow as compared to the downstream sections resulting the lesser velocity at upstream sections. However, Bed shear stress values increase for lower flow depths and decrease for higher flow depth cases. This is because the effect of accumulated and higher value of friction factor is produced at the downstream sections. For higher flow depths, the effect of bottom friction decreases maintaining the similar trend of depth-averaged velocity.

\section{References}

1. K. Mahmood, V. Yevjevich, eds., Water Resour. Publ. Fort Collins, Colo., 1, (1975).

2. T. C. Song, W. H. Graf, J. of Hyd. Eng., 122, 3, 141-154 (1996).

3. H. Tu, W. H. Graf, In Proc. of the Inst. of Civil Engineers: Water Mari. and Energy, 96, 63-69 (1992).

4. K. T. Lee, Y. L. Liu, K. H. Cheng, Hydro. processes, 18 13, 2439-2454 (2004).

5. M. A. Ahanger, G. L. Asawa, M. A. Lone, J. of Hyd. Res., 46, 5, 628-635 (2008).

6. G. Bombar, Ş. Elçi, G. Tayfur, M. Ş.,Güney, A. Bor, J. of Hyd. Eng., 137, 10, 12761282 (2011).

7. R. L. Martin, D. J. Jerolmack, Water Resour. Res., 49, 3, 1314-1333 (2013).

8. L. Wang, A. J. Cuthbertson, G. Pender, Z. Cao, Int. J. of Sed. Res., 30, 4, 306-320 (2015).

9. Z. Wang, B. Lin, F. Nestmann, Int. J. Sed. Res, 12, 1, 1-15 (1997).

10. K. Devi, K. K. Khatua, Flow Meas. and Instru., 50, 147-157, (2016).

11. J. Preston, J. Aeronaut. Soc, 58, pp.109-121 (1954).

12. J. R. Khuntia, K. Devi, K. K. Khatua, Ind. J. of Sc. \& Tech., 9, 46, (2016). 